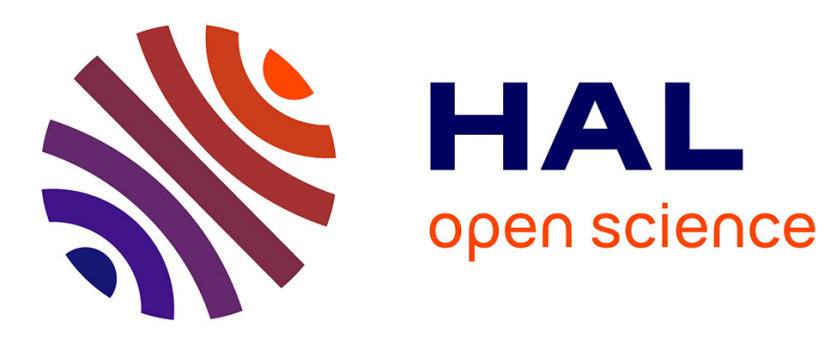

\title{
Bacterial and cellular RNAs at work during Listeria infection.
}

\author{
Nina Sesto, Mikael Koutero, Pascale Cossart
}

\section{To cite this version:}

Nina Sesto, Mikael Koutero, Pascale Cossart. Bacterial and cellular RNAs at work during Listeria infection.. Future Microbiology, 2013, 9 (9), pp.1025-37. 10.2217/FMB.14.79 . pasteur-01161885

\section{HAL Id: pasteur-01161885}

https://hal-pasteur.archives-ouvertes.fr/pasteur-01161885

Submitted on 9 Jun 2015

HAL is a multi-disciplinary open access archive for the deposit and dissemination of scientific research documents, whether they are published or not. The documents may come from teaching and research institutions in France or abroad, or from public or private research centers.
L'archive ouverte pluridisciplinaire HAL, est destinée au dépôt et à la diffusion de documents scientifiques de niveau recherche, publiés ou non, émanant des établissements d'enseignement et de recherche français ou étrangers, des laboratoires publics ou privés. 


\section{Future"s
Medicine $\quad$ Peer Review Paper}

\section{Bacterial and cellular RNAs at work during Listeria infection}

\section{Abstract/Summary}

Listeria monocytogenesis an intracellular pathogen that can enter and invade host cells. In the course of the infection, RNA-mediated regulatory mechanisms provide a fast

6 and versatile response for both the bacterium and the host. Theyregulate a variety of

7 processes such as environment sensing, and virulence in pathogenic bacteria as well as

8 development, cellular differentiation, metabolism and immune response in eukaryotic

9 cells. The aim of this review is to summarize first the RNA-mediated regulatory 10 mechanisms playing a role in theListerialifestyle and invirulence and then the host 11 miRNA response toListeria infection.Finally, we discuss thepotential crosstalk between 12 bacterial RNAs and host RNAregulatorymechanisms as new mechanisms of bacterial 13 virulence.

15 Keywords

16 virulence, sRNA, asRNA, riboswitch, thermosensor, excludon, CRISPR,miRNA, immune 17 response,RNA secretion 


\section{Future"y Peer Review Paper}

\section{Introduction}

The human pathogen Listeriamonocytogenes ranks among the best-known invasive bacteria. In the course of the infection of susceptible individuals, primarily elderly and pregnant women, Listeria can cross the intestinal, blood-brain and fetoplacental barriers causing a disease known as listeriosis. Listeriais an intracellular pathogen that has the ability to invade, survive and actively multiply within professional phagocytes and a number of non-phagocytic cells. During infection, Listeria produces a plethora of virulence factors whose production is spatio-temporally regulated by both protein-mediated and RNA-mediated regulatory mechanisms. The secreted and surface exposed virulence factors allow Listeria to deploy a number of sophisticated strategies to compromise the cell and also promote its survival. These involve adherence and entry in to the mammalian cells by exploiting host cell receptorsand signalling events,manipulation of the immune defence mechanisms, impairment of organelle dynamics and interference with post-translational modifications. Recent studies have highlighted that Listeriacould also reprogram the host cell transcription by inducing histone modifications, chromatin remodelling and by impactingon the miRNA expression profiles of infected cells and tissues[1-4].

The mechanisms underlying mammalian and bacterial gene regulationsshare remarkable similarities. Besides protein regulators, non-coding RNAs (ncRNAs) are increasingly recognized as highly versatile regulatory components in both eukaryotes and prokaryotes. Their roles range from transcription regulation to translation repression and chromatin remodelling. Prokaryotic ncRNAs have important roles in mediating the response to environmental cues, in performing housekeeping functions andin controllingthe virulence in pathogenic bacteria[5, 6]. The first ncRNAs in Listeria were identified by co-immunoprecipitation with Hfq, a small RNA-binding protein 


\section{Future
Medicine $^{-} \quad$ Peer Review Paper}

required for small RNAsfunction in bacteria[7]and by an in-silico based approach [8]. However, major progress in the discovery of regulatory RNA transcripts were made with the use of high-density tiling arrays and RNA-Seq[9-13], which provided apicture of the whole Listeria transcriptome in multiple conditions. This led to the annotation of hundreds of regulatory RNAs in Listeria among which some play regulatory roles in virulence[14]. Likewise, eukaryotic ncRNAs, including microRNAs (miRNAs) and long non-coding RNAs (lncRNAs), regulate a variety of processes such as development, cellular differentiation, metabolism, immune response as well as viral and parasite infections [15-18]. More than 1000 miRNAs are annotated in the human genome and it is predicted they could regulate $60 \%$ of the human transcriptome [19].

The aim of this review is to highlight the importance of RNA-mediated regulatory mechanisms, both in Listeria and in the infected mammalian cell, which play a role in the subtle pathogen-host interactions, dictating the progress of the infection. We will first review the known RNA-mediated regulatory mechanisms controlling theListeria virulence and then our current knowledge on the expression of eukaryotic miRNAs in the response to Listeria infection. Finally, we will speculate on the potential crosstalk between bacterial and host RNA regulatory mechanisms during the infection.

\section{TheListeria regulatory RNA repertoire important for the virulence process}

Bacterial regulatory RNAs can be classified into several groups: 5'-untranslated regions (5'-UTRs) of mRNAs, cis-encoded antisense RNAs (asRNAs), trans-acting small RNAs (sRNAs) and the more recently described,Clustered Regularly Interspaced Short Palindromic Repeats (CRISPRs). In the following section, we will briefly describe the main regulatory principles characteristic for each class, and further detail the specific examples of molecular mechanisms found to have an impact on Listeria virulence. 


\section{$\begin{array}{ll}\text { Future } & \text { Peer Review Paper } \\ \text { Medicine } & \text { Peer }\end{array}$}

The5'-untranslated region (5'UTR) of an mRNAis located between the

transcriptional start site (TSS) and the translational initiation site. It harbours the Shine-

Dalgarno (SD) sequence to which the ribosome binds and initiates protein translation. In prokaryotes, transcription and translation are coupled and therefore, many 5'-UTRshave evolved as efficient gene expression regulators that sense physicochemical signals (e.g. thermosensors and riboswitches), or can bind proteins and RNA regulatorsacting before completion of the transcription/translation of the gene. The precise length of all 5'-UTRs in theListeria transcriptome has been recently determined by high resolution mapping of the TSSs in a genome-wide manner [13]. Agroup of 101 genes with an unusually long 5'-UTR (>100nt) includes10 known Listeria virulence factors[13] among which some have been extensively studied.

The main regulator that orchestrates the Listeria infectious process is PrfA ( Positive regulatory factor $\underline{\mathrm{A}}$ ), a transcription factor of the Crp/Fnr familythat induces theexpression of major known virulence genes. Its expression is tightly regulated by two RNA-mediated mechanisms operating at its 116 nucleotide long 5'-UTR (Figure 1). First, the 5'-UTR of $\operatorname{prfA}$ mRNA is a thermosensorelement, whichadopts a stable stem-loop structure at a low temperature, therebyoccluding the SD sequence and preventing binding of the ribosome. When the temperature increases to $37^{\circ} \mathrm{C}$, the stem-loop melts into an alternative secondary structure, allowing the ribosome to access the SD sequence, leading to the translation of theprfA mRNA and to the subsequent induction of a number of virulence genes [20]. A second mechanism of prfA expression regulation involves a trans-acting riboswitch-derived element. Typically, riboswitches are 5'UTR elements that, upon binding of aligand (tRNA, ions or metabolites),undergo conformational changes and affect the transcription or the translation of a nascent mRNA transcript.Riboswitch-regulated transcripts usually encode genesinvolved in the 


\section{Future
Medicine}

biosynthesis of the molecule that regulates the riboswitch[21]. In the case of Listeria, the short transcript of theSAM(S-adenosyl-methionine)riboswitchSreA, which regulates in cis the expression of genes involved in methionine and cysteine metabolism, interacts in trans with the 5'UTR of prfAmRNA, approximately 80 bases upstream of the SD site.This binding decreases the translation of $\operatorname{prfA}[22]$. This is the first, and so far unique example of such a dual function for a riboswitch element. The PrfAthermosensor-mediated temperature sensingand the riboswitch-mediated nutrient sensing allow Listeria to sense its environment and accordingly regulate PrfA expression, turning on theexpression of crucial virulence genes solely when required in the host.

Cis-encoded antisense RNAs (asRNAs)are heterogeneous groups of regulatory transcripts that originate from the DNA strand opposite to genes they regulate, or can arise from overlapping 5'UTRs and 3'UTRs of adjacent genes. In all cases, cis-encoded antisense transcripts have perfect complementarity with the sense transcript and are denoted as antisense RNAs (asRNAs). Their length varies dramatically, ranging from less than a hundred to several thousand nucleotides, overlapping one or several genes. In Listeria there are 95asRNA transcripts annotated to date, whose function is in most cases unknown.

Of note, for some of the long asRNA transcripts, a recurring pattern was observed in at least 13 characteristic antisense containing genomic loci, which led to the definition of a novel concept in bacterial gene regulation named excludon[13, 23](Figure 2A). The excludon is a locus encoding two divergent genes with related and often opposite function and a long asRNAof one gene, thatalso contains the mRNA of the divergentadjacentgene. In two cases, it was demonstrated thatthe asRNA negatively affects the expression of the overlapped gene whereas its distal part constitutes a functional mRNA and positively contributes to the expression of the adjacent gene[12, 


\section{$\begin{array}{ll}\text { Future } & \text { Peer Review Paper } \\ \text { Medicine } & \text { Peer }\end{array}$}

13]. In other words, an excludon functions as a genomic togglewhere a single transcript governs the mutually exclusive expression of adjacent genes that generally have opposing functions. For example, an excludon regulatesthe transcription of flagellar/motility genes[12](Figure 2A). Flagella are important mediators of Listeria pathogenicity[24]but at the same time, they are strong inducers of the host immune response[25] and therefore, their tight regulation is crucial for Listeria survival during infection.

The diversity of asRNA-mediated regulation is further illustrated by the remarkable example of a riboswitch-regulated asRNA in Listeria [26](Figure 2B). A vitamin B12-dependent riboswitch regulates the expression of the asRNAAspocR, which overlaps the gene encoding PocR, a transcription factor thatactivates transcription of the genes mediating propanediol catabolism $(p d u)$ and vitamin B12 biosynthesis (cob). Vitamin B12 is an important cofactor for the activity of diol-dehydratase, an enzyme required for propanediol catabolism. In the presence of B12, the riboswitch terminates prematurely AspocR transcription, allowing the subsequent expression of $p o c \mathrm{R}$, whereas in the absence of B12, AspocR is fully transcribed, thus negatively regulating PocR production. Interestingly, the negative regulation of pocRexpression was observed whenAspocR was expressed in trans, indicating that it likely interferes with the transcription or translation initiation of pocR. Overall, this mechanism ensures that PocR is produced uniquely when the B12 cofactor is available, allowing the subsequent activation of the propanediol catabolism genes. Propanediol, together with the closely related metabolite, ethanolamine,constitute important nutrient sources for bacterial enteropathogens [27]. Recently, it was shown that during intestinal infection by Salmonella enterica, use of ethanolamine as a carbon source enables the bacterium to outcompete the intestinal microbiota that cannot use this nutrient[28]. Accordingly, the 


\section{$\begin{array}{ll}\text { Future } & \text { Peer Review Paper }\end{array}$}

expression of genes involved in the utilization of propanediol and ethanolamine are upregulated during intracellular growth of Listeria [29] and more interestingly,also in Listeria isolated from the intestine of germ-free mice pretreated with lactobacilli [30], suggesting their important role in Listeria virulence.

Trans-encoded small RNAs (sRNAs) are transcribed fromintergenic regions, or are generated by processing of the 5'UTRs or 3'UTRs of mRNAs, and in contrast to the cis-asRNAs, they regulate targets encoded at distant genetic loci. The most extensively studied trans-encoded sRNAs are those targeting mRNA molecules. They can also bind and sequester proteins. The interaction between a sRNA and its target mRNA is mediated by short, imperfect base pairing and can eitherpositively or negatively affect the target transcript[6]. In Listeria there are more than 150 transcripts annotated as sRNAs and similarly to the asRNA transcripts, their biological function is in most cases unknown[7-13]. However, important information about their expression conditions, and hints into their potential function, was obtained by extensive tiling array analysis using bacteria grown in four physiologically relevant conditions (exponential phase, stationary phase, hypoxia and low temperature), or isolated from intestine of axenic mice or bacteria grown in blood of human donors. The same panel of conditions was used to analyse mutants of known virulence regulators and RNA binding proteins $(\Delta p r f A, \Delta \operatorname{sig} B, \Delta h f q)[12,13]$. Likewise, RNA sequencing with the 454 technology of Listeria grown in macrophages, revealed sRNAs whose expression is induced during the intracellular phase of the infection [10]. Assuming that sRNAsaregenerally induced in conditionsrelevant fortheir biologicalrole, these studies highlighted sRNAs whose function might be important for Listeria virulence, and enabled the prediction of their potential regulators.In addition, a number of sRNAs annotated in the $L$. monocytogenesgenome are not conserved in the closely related, but non-pathogenic 


\section{Future
Medicine $\quad$ Peer Review Paper}

species L. innocua[13]. Comparative genomic studies of the two species have been previously used to identify a number of Listeria virulence factors[1, 31], and it is thus tempting to speculate that L. monocytogenes-specific sRNAs would play a role in virulence. Indeed, nearly all sRNAs shown to have a role in virulence are absent from thenon-pathogenic species. Among these, Rli33-2 and Rli50, when deleted, led to an attenuated virulence phenotype in murine macrophage infection as well as in mouse and butterfly larvae infection models[10]; similarly, a deletion mutant of Rli38 resulted in an attenuated virulence phenotype in orally inoculated mice [12]. Another sRNA absent from L. innocuaRli27has been recently shown to positively regulate the expression of Imo0514, encoding an LPXTG surface protein enriched in the cell wall of intracellular bacteria[32]. This regulation occurs by mechanism involving pairing of Rli27 with the 5'UTR of the Imo0514 mRNA. Remarkably, Imo0514 transcript is detected in two variants, differing in length and in relative amount in extra- and intracellular bacteria. Only the long version, more abundant in intracellular bacteria, contains the 5'-UTR recognized by the Rli27,rendering this regulation possible only inside the host cell (Quereda, et al.PLoS Genetics, in revision). Some sRNAs might have multiple target genes, as shown in the case of LhrA which affects expression of nearly 300 genes and directly regulates expression of Imo0850, Imo0302 encoding proteins with an unknown function and chiAencoding a chitinase[33, 34]. ChiA contributes to Listeria pathogenesis [35].

It is worth mentioning that some Listeria sRNAs annotated as non-coding transcripts encode putative open reading frames (ORFs) for small, often very basic polypeptides, whose function is unknown. As reported for other species, these peptides could act as signaling molecules involved in bacterial communication or might play a role in bacterial virulence [36-38]. 


\section{Future
Medicine $\quad$ Peer Review Paper}

CRISPR/Cas systems (Clustered Regularly Interspaced Short Palindromic

195 Repeats)provide bacteria and archaea with specific mechanisms of RNA-mediated

196 adaptive immunity against invading nucleic acids, i.e. viruses and conjugative plasmids.

197 Typically, CRISPR systems are composed of arrays of identical repeat sequences,

198 interspaced with non-repetitive variable spacers, coupled with clusters of CRISPR-

199 associated (cas) genes that are involved in all steps of CRISPR function.At the core of

200 CRISPR functionality are the spacers, short DNA segments originating from a foreign

201 DNA, which when transcribed provide a specific guide for CRISPR-mediated DNA/RNA

202 silencing of the corresponding invading virus or a plasmid[39]. Listeria species encode

203 three different CRISPR systems[40-42].CRISPR-I and/or CRISPR-II are present in

204 someListeria strains and are always associated withcasgenes. Their identified spacers

205 match uniquelyListeria bacteriophages.The third CRISPR,the RliB-CRISPR (previously

206 annotated as a sRNA named RliB)is present in all so far sequenced Listeria strains but is

207 never associated with acaslocus.However, both in the cas-less Listeria strains and in

208 those encoding a complete set of cas geneselsewhere in the genome(adjacent either to

209 CRISPR-I or CRISPR-II), the RliB-CRISPR is expressed and processed [42]. Surprisingly,

210 this processing is governed by the polynucleotide phosphorylase (PNPase), a genome-

211 encodedbi-functional enzyme harboring both3' to 5' exoribonuclease and 3' polymerase

212 activities[43]. The identification of RliB-CRISPR processing by PNPaserevealed a unique

213 role for this enzyme in bacterial "CRISPRology". Similarly to CRISPR-I and CRISPR-

214 II,RliB-CRISPR targets Listeria bacteriophages. Functional studies of RliB-CRISPR

215 showed it has a DNA-interference activity. Singularly, its activity requires that both

216 PNPase and the casgenes belonging to CRISPR-I are present in the genome. RliB-CRISPR

217 and CRISPR-I share a similar repeat sequence, suggesting they might share the same

218 enzymatic machinery required for their function[42]. Interestingly, RliB-CRISPR is 


\section{\begin{tabular}{l}
$\begin{array}{l}\text { Future } \\
\text { Medicine }\end{array} \quad$ Peer Review Paper \\
\hline
\end{tabular}}

As a result of high throughput transcriptome studies a comprehensive overview

238 available(http://www.weizmann.ac.il/molgen/Sorek/listeria_browser/). The functional

239 studies have revealed a broad diversity of regulatory mechanisms underlying the action 240 of individual RNAs. A future challenge will betodecipher the biological function of the 241 many annotated, but so far unexploredncRNAs in Listeria. Altogether, recent research on 242 Listeria RNA-mediated regulations, as well as theimpressive number of studies in other 


\section{$\begin{array}{ll}\text { Future } & \text { Peer Review Paper } \\ \text { Medicine } & \text { Peer }\end{array}$}

244 virulence process.

\section{The mammalian miRNA response to Listeria infection}

MicroRNAs (miRNAs) are 21-24 nucleotide long regulatory RNAs present in animals, plants and viruses. They are derived froma long primary transcript (primiRNA) that is first processed in the nucleus by the RNaseIII family dsRNAendonucleaseDrosha into a pre-miRNA. The pre-miRNA is exported in the cytoplasm and further cleaved by another member of the RNase III family, Dicer. Processed single stranded miRNAs associate with the RNA-induced silencing complex (RISC), consisting of multiple proteins among which members of the argonaute protein family have RNAse activities, and are central to the RISC function [49]. The miRNA interaction with the target mRNA is mediated by imperfect complementarity between the 3'-UTR of the target transcript and the miRNA-RNase ribonucleoprotein complex andit typically leads to translation inhibition and/or degradation of the target gene. To achieve effective processing, this interaction requires a so called "seed region", a sequence harboring perfect complementarity with the 5 '-end of the miRNA [50].

As previously mentioned, miRNAsare involved in various physiological and pathological processes. Their role during bacterial infections of animals has only recently started to be investigated with several pioneering studies, e.g. in Helicobacter pylori, Salmonella entericaand Mycobacterium avium[51-54]. The role of miRNAs during L. monocytogenesinfection has been addressed both in cultured cells $[55,56]$ as well as in vivoin mice models[30, 54, 57]. Here, those studies will be presented in an order, which may look awkward butfollows the course of the natural infectious process. 


\section{Future
Medicine $^{2} \quad$ Peer Review Paper}

Listeria infection starts by ingestion of contaminated food, which delivers the

267 bacterium to the intestinal lumen of the host. There, Listeria competes with the

268 intestinal microbiota in order to colonize the lumen, cross the intestinal barrier and

269 further disseminate to deeper organs. A study examining the impact of lactobacillion

270 orally acquired listeriosis [30]and a study addressing the role of microbiota in the

271 regulation of miRNA expression in the ileum of Listeria infected mice[57] identified a

272 particular expression response of protein-coding genes and interestingly, of miRNA

273 regulators (Figure 3).These two comprehensive studies represent the firstin vivo

274 evidence of a particular miRNA signature induced during orally acquired Listeria

275 infection. More interestingly, expression of several infection-induced miRNAs, such as

276 miR-192, miR-143, miR-148a, miR-200b and miR-200cwas affected by the presence of

277 lactobacilli or the host microbiota, demonstrating the important role of intestinal

278 bacteriain the modulation of the host miRNA response to infection [30, 57]. A

279 singlemiRNA family wascommon to both studies, i.e. miR-200, which has been reported

280 to induce epithelial differentiation and suppress the epithelial-mesenchymal transition

281 in several types of cancer [58] as well as to play a significant role during the Helicobacter

282 infection [59]. ThemiRNA target prediction results crossed with the transcriptomic data

283 revealed that miR-200 and other regulated miRNAs could target genes with a function in

284 immunity as well asgenes whose function could be related to the infection. Some

285 miRNAs could target the same protein-coding genes, suggesting the existence of

286 complex miRNA-mRNA regulatory networks[30, 57]. Importantly, expression of some of

287 the predicted targets anti-correlated with the expression of the putative miRNA

288 regulator during the Listeria infection,e.g. an immune response transcription factor

289 (Atf3), a retinoic acid induced protein that plays a role in epithelial cell differentiation

290 (Gprc5), an enzyme involved in fucosylation of epithelial cells (Fut2), a protein that plays 


\section{$\begin{array}{ll}\text { Future } & \text { Peer Review Paper }\end{array}$}

a role in intestinal inflammation $(N t 5 e)$ and an RNA editing enzyme of the miRNA and

292 small interfering RNA (siRNA) pathways (Adar),supporting that predicted interactions

293 indeed might occur in the infected tissue. Moreover, a number of interactions

294 werepredicted to occur both in mice and humans. Their conservation in significantly

295 distant organisms furthermore supports the validity of their biological function.

Following infection, Listeria needs to overcome the rapidly triggered host innate

immune response. Early resistance to the Listeria infection relies in part onthe production of interferon- $\gamma($ IFN- $\gamma$ ) by natural killer (NK) cells, which promotesthe

activation of macrophages [4]. Ma et al.reported that IFN- $\gamma$ expression is regulated by

miR-29, which directly binds within the 3'UTR of the ifn- $\gamma$ mRNA. Interestingly, mice

infected with Listeria showed decreased expression of miR-29 and a relevant increase in

the production of IFN- $\gamma$. Moreover, transgenic mice expressing a sponge target construct

that competes with endogenous miR-29 targets, displayed a lower bacterial burden in

comparison to the wild type mice, indicating that lower expression of miR-29 and higher

IFN- $\gamma$ production in NK cells, promoted host resistance to Listeria infection [56].

In the following steps of the infection, Listeria is internalized by macrophages.

During the infection of bone marrow derived macrophages (BMDMs), Listeria induces expression of 13 miRNAs among which miR-155, miR-146a, miR-125a-3p/5p and miR149 are the most significantly up-regulated [54]. This induction occurs already when

bacteria are in the phagosome and is mediated by MyD88, a universal adaptor protein used by almost all Toll-like receptors (TLRs) to activate the transcription factor NF- $\mathrm{B}$, a

312 key regulator of the immune response to the infection. Indeed, miR-155 and miR-146 313 are known modulators of the immune response in macrophages $[60,61]$, whereas the 314 functions of miR-125a-3p, miR-125a-5p and miR-149 have not yet been described. 315 Target prediction analysissuggested that all 5 miRNAs could potentially interact with 


\section{\begin{tabular}{l}
$\begin{array}{l}\text { Future } \\
\text { Medicine }\end{array} \quad$ Peer Review Paper \\
\hline
\end{tabular}}

mRNAs encoding immune-related proteins. For instance, miR-125a-3p and miR-125a-5p could respectively target the interleukin-1 receptor 1 (Il-1R1) and IL-6 receptor (Il-6 R) transcripts[54].

Thewholeinfectious process relies on the Listeria capacity to enter nonphagocytic cells. During infection of epithelial cells, Listeria induces expression of miR155, miR-146b and miR-16 and decreases expression of let-7a1 and miR-145, all of which are also implicated in the regulation of immune-related genes. Interestingly, several major Listeria virulence determinants, the surface internalinsInlA and InlB as well as the secreted toxin listeriolysin 0 (LLO), are implicated in the regulation of the above-mentioned miRNAs [55]. Purified LLO could fully reproduce the Listeria-induced miRNA expression profile whereas aListeria deletion mutant for inlA and inlBled to decreased expression of miR-155, suggesting a putative role for internalins or Listeria entry in miRNA regulation [55].

After a primary infection, Listeriastimulates a strong memory CD8 $^{+}$T-cells response, allowing a rapid clearance of the bacteria from the infected tissues upon a reinfection [62]. Interestingly, in knock-out mice not expressing miR-155, the CD8+ T-cell response is significantly reduced following Listeriainfection, indicating that this miRNA has an important role in the regulation of the $\mathrm{CD}^{+}$-mediated response to the infection by an intracellular pathogen [63]. However, the direct effect of Listeria on the expression of the miR-155 in this cell type is not known.

A significant effort has been made to identify numerous mammalian miRNAs, both in vivo and in different cellular models, whose expression is regulated during Listeria infection. Not surprisingly, the miRNA profile induced in the intestinal tissue is different from thatinduced by aListeria infection in different cell lines. Nevertheless, the regulated miRNAssharesimilar functions (either predicted or experimentally described), 


\section{$\begin{array}{lll}\text { Future } & \text { Peer Review Paper }\end{array}$}

mainly regulating immune genes. Indeed, miRNAs are key components of the innate

342 immune response $[15,64]$ and previously mentioned studies suggest that miRNAs are

343 crucial regulators of host defenses against intracellular bacterial infection, but also

344 potential targets for the pathogen-induced manipulation and/or evasion of the host

345 immune response. Similarly to the miR-200 family, which is specific tothe intestinal

346 miRNA response, miR-155 and miR-146 appear to beinduced by Listeria in different

347 cellular contexts - BMDMs and epithelial cells. Interestingly, these miRNAs are also

348 induced by other bacterial pathogens, e.g. Helicobacter pylori [51, 65], Salmonella

349 enterica[52], Mycobacterium avium[53] as well as viral and fungal pathogens[66, 67],

350 indicating their universal role in the common immunity pathways shared by different

351 pathogens. In line with this remark, the expression of miR-155 and miR-146 is

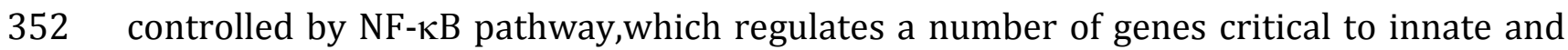

353 adaptive immunity, cell proliferation, inflammation, and tumor development[64].

Althoughidentification of the miRNA profile during Listeria infection is clearly

underway, a future challenge will be to decipher the molecular mechanism underlying

themiRNA expression changesupon infection as well as to identify their relevance for

357 theListeriainfectious process.

III. A potential crosstalk of bacterial and mammalian regulatory RNAs during

Listeria infection

As emphasized in the introduction, Listeria has evolved a number of sophisticated

361 strategies to establish anefficient infection and promote its survival in the host.

362 TheListeriaeffectors known to be involved in these complex rolesincludeLL0, which

363 forms pores, promotes escape from the vacuole, triggers histone modifications,other 364 post-translational modifications and mitochondrial fragmentation, ActA which allows 


\section{\begin{tabular}{l}
$\begin{array}{l}\text { Future } \\
\text { Medicine }\end{array} \quad$ Peer Review Paper \\
\hline
\end{tabular}}

Listeria to move intracellularly,InlC that interferes with NF- $\kappa \mathrm{B}$ activation andLntA, which enters the host nucleus and induces chromatin remodeling.All these virulence factors are all proteinaceous molecules[1]. It is tempting to speculate that numerousListeria ncRNAs for which the functions have not been identified, might as well act as such effectors i.e.RNA virulence factors that could be actively delivered to the host cell and manipulate host regulatory pathways.

While such RNA effectors have never been described in bacterial pathogens, and while it was neverformally demonstrated that aspecific bacterial RNA is actively delivered to the host cell, there is a strong logic supporting the existence of bacteria-host RNA-mediated communication.First, many pathogenic bacteria as exemplified by Listeria, enter the host cell and therefore haveaccess to different cellular compartments. Second, they possessvarious systems of export/secretion that can secreteproteins, and also nucleic acids.For instance, it has been shown thatNeisseria gonorrhoeaecan secrete single stranded DNA by the type IV secretion system (T4SS) [68].In the case of Listeria, it has been shown that it can secrete small nucleotides such as c-diAMP[69], and it was recentlydemonstrated it can also release DNA and RNA during the infection of the host cell [70]. Third, regulatory RNAs offer a general mechanism to interfere with mammalian regulation.For example, a bacterial RNA could bind a host miRNA and inhibit its function or it could mimic a mammalian miRNA, therebyovertaking the miRNA-machinery andaffecting the expression ofthehost genes. As emphasized in the preceding section, miRNAs are key components of the immune response $[15,64]$, which makes them exceptional targets for such pathogen-induced manipulation.As shown withListeria and other pathogens, their expression is indeed significantly affected upon infection. Alternatively, one should not exclude the possibility that RNA virulence 


\section{\begin{tabular}{l}
$\begin{array}{l}\text { Future } \\
\text { Medicine }\end{array}$ Peer Review Paper \\
\hline
\end{tabular}}

effectors mightaffect function of other host ncRNAs, such as lncRNAs, or could bind and sequester host regulatory proteins as well as have other, yet unanticipated functions. A direct evidence of such host-pathogen cross-kingdom RNA-mediated regulation comes from some remarkable studies of viral and fungal pathogens. Herpesvirus saimiri(HVS) and also cytomegalovirus (MCMV) express RNAs that interact and lead to degradation of the host miR-27, consequently affecting the expression of miR-27 target genes [71-73]. A fungal pathogenBotrytis cinerea expresses a set of sRNAs, whichmimic host miRNA and bind to Argonaute 1 protein (AG01), selectively silencinga subset of host immunity genes [74].

It has been recently shown that during infection, viable Listeria can release nucleic acids in the host cytoplasm [70]. As said above, this occurs also for other pathogenic bacteria and is essential for generation of anti-microbial immunity[75]. Cytosolic Listeria canreleasethe second messenger c-di-AMP [69] as well as RNA/DNA $[70,76]$ that are recognized by the sensors RIG-I, MDA-5 and STING, resulting in the production of IFN. Bacterial RNAsare exceptionally good PAMPS (Pathogen Associated Molecular Patterns - molecules associated with pathogens that are recognized by the innate immunity) as they differ from the eukaryotic RNA by the nature of their 5 '-end, whichinstead of a trimethylguanosine cap,consists of a triphosphate. RIG-I has been shown to recognizetriphosphorylatedListeria RNA [76]. More importantly, translocation of RNA during the Listeria infection was visualized in the host cytosol using a sensitive RNA fluorescence technique [76] and this translocation was shown to be dependent on the activity of SecA-2 [70], an auxiliary protein secretion system that promotes secretion of several virulence factors [77] as well as other genes whose expression is strongly induced in vivo [78].Thesedata strongly indicate that the translocation of nucleic acids 


\section{Future
Medicine $\quad$ Peer Review Paper}

during the infection is not a product of bacterial lysis but might be governed by an active

414 bacterial process.

Even though these studies provide evidence that ListeriaRNA has an access and is

actively delivered to the host cytosol during the infection, nothing is known about the specificity of this process andits potential benefit for the pathogen. A secreted

RNAvirulence factor has never been identified in bacteria and this exciting hypothesis remains to be explored in the future.

\section{Conclusions}

Decades of research led to the discovery of numerous Listeria molecular strategies, whichhave been selected during the billions of years of pathogen-host coevolution, to establish a successful infection. NcRNAs are versatile regulators important for the Listeria virulence gene expression, metabolism regulation and the interaction with the host.Similarly, eukaryotic miRNAs are potent regulators controlling the expression of the human genome with an important accent on the immune response regulation.This makes them a potent target for pathogen manipulation.Indeed, during different phases of the Listeria infectious process,the hostmiRNA expression is significantly altered. Similarity between prokaryotic and eukaryotic RNA-mediated molecular mechanisms and the accessibility of the host RNA machinery to the intracellular Listeria highlights a possibility of the interspecies RNA crosstalk between the pathogen and the host.

\section{Future perspectives}

As revealed by transcriptomic studies, most of the Listeria genome is expressed, however little is known about the biological function of many transcripts.Exploration of 


\section{$\begin{array}{ll}\text { Future } & \text { Peer Review Paper } \\ \text { Medicine } & \text { Paper }\end{array}$}

understanding of Listeria interaction with the mammalian miRNA regulatory pathways

441 is still in its infancy. Most of the studies performed so far are descriptive, yet they

442 achieved significant progress in recording miRNA expression changes in the host upon

443 Listeria infection. A future challenge will consist in deciphering(a) how Listeria targets a

444 specific set of miRNAs during a particular phase of the infectious process, (b) what are

445 the regulated target genes, and (c) what is the direct benefit for the bacterium as well as 446 for its virulence.

Up to now, the knownListeria virulence effectors are protein molecules. Being 448 aware of the versatile nature and immense regulatory capacity represented by RNA 449 molecules, and supported by the studies in viral and fungal pathogens, one can 450 imaginethe exciting hypothesis that such secretedvirulence effectors might also be 451 RNAs. The identification of such RNA effectors would open new horizons in the studies 452 of pathogen-host interactions and the field of cellular microbiology. 


\section{Future" $\quad$ Peer Review Paper}

\section{Executive summary:}

456 Listeria regulatory RNA repertoire important for the virulence process

- Listeria monocytogenes is an invasive pathogenic bacteriumwhose virulence factors expression is controlled by RNA-mediated regulatory mechanisms.

- The expression of the main Listeriavirulence regulator PrfA is regulated by an RNAthermosensor and a trans-acting SAM riboswitch.

- In Listeria, 13long asRNAs named excludon,whichregulate expression of genes with opposite functions and act as fine-tuning regulatory switches, have been identified.

- The Listeria vitamin B12 biosynthesis and propanediol catabolism, an important nutrient during the intestinal phase of the infection, is controlled by the transcription factor PocR. Expression of PocR is regulated by theB12riboswitchregulated asRNAAsPocR.

- There are more than 150 annotated sRNAs in Listeria with mostly unknown functions.Forsome of themit has been shown a role in virulence.

- Listeria RliB-CRISPR system, which is processed with the help of chromosomally encoded polynucleotide phosphorylase (PNPase), has a role in the virulence

The mammalian miRNA response to Listeria infection

- During the infection, Listeria induces expression changes of the host miRNAs, induced listeriosis and miR-155 and miR-146 appear to be induced by Listeria in different cellular contexts. 


\section{Future
Medicine $\quad$ Peer Review Paper}

A potential crosstalk of bacterial and mammalian regulatory RNAs during Listeria infection

- Viable Listeria can release nucleic acids in the host cytoplasm which might have a regulatory function to favor the infection.

\section{References}

1. Cossart P: Illuminating the landscape of host-pathogen interactions with the bacterium Listeria monocytogenes.Proc Natl Acad Sci U S A 108(49), 19484-19491 (2011).

2. Mostowy S, Cossart P: Virulence factors that modulate the cell biology of Listeria infection and the host response.Adv Immunol 113, 19-32 (2012).

3. Lebreton A, Cossart P, Bierne $\mathrm{H}$ : Bacteria tune interferon responses by playing with chromatin.Virulence 3(1), 87-91 (2012).

4. Stavru F, Archambaud C, Cossart P: Cell biology and immunology of Listeria monocytogenes infections: novel insights.Immunol Rev 240(1), 160-184 (2011).

5. Caldelari I, Chao Y, Romby P, Vogel J: RNA-mediated regulation in pathogenic bacteria.Cold Spring Harb Perspect Med 3(9), a010298 (2013).

6. Storz G, Vogel J, Wassarman KM: Regulation by small RNAs in bacteria: expanding frontiers.Mol Cell 43(6), 880-891 (2011).

7. Christiansen JK, Nielsen JS, Ebersbach T, Valentin-Hansen P, Sogaard-Andersen L, Kallipolitis BH: Identification of small Hfq-binding RNAs in Listeria monocytogenes.Rna 12(7), 1383-1396 (2006).

8. Mandin P, Repoila F, Vergassola M, Geissmann T, Cossart P: Identification of new noncoding RNAs in Listeria monocytogenes and prediction of mRNA targets.Nucleic Acids Res 35(3), 962-974 (2007).

9. Behrens S, Widder S, Mannala GK et al.: Ultra Deep Sequencing of Listeria monocytogenes sRNA Transcriptome Revealed New Antisense RNAs.PLoS One 9(2), e83979 (2014).

10. Mraheil MA, Billion A, Mohamed W et al: The intracellular sRNA transcriptome of Listeria monocytogenes during growth in macrophages.Nucleic Acids Res 39(10), 4235-4248 (2011).

11. Oliver HF, Orsi RH, Ponnala L et al.: Deep RNA sequencing of L. monocytogenes reveals overlapping and extensive stationary phase and sigma B-dependent transcriptomes, including multiple highly transcribed noncoding RNAs.BMC Genomics 10, 641 (2009).

12. Toledo-Arana A, Dussurget 0 , Nikitas G et al: The Listeria transcriptional landscape from saprophytism to virulence. Nature 459(7249), 950-956 (2009).

13. Wurtzel O, Sesto N, Mellin JR et al.: Comparative transcriptomics of pathogenic and nonpathogenic Listeria species. Mol. Syst. Biol. 8, 583 (2012).

14. Mellin JR, Cossart P: The non-coding RNA world of the bacterial pathogen Listeria monocytogenes.RNA Biol 9(4), 372-378 (2012).

15. O'connell RM, Rao DS, Chaudhuri AA, Baltimore D: Physiological and pathological roles for microRNAs in the immune system. Nat Rev Immunol 10(2), 111-122 (2010).

16. Sun K, Lai EC: Adult-specific functions of animal microRNAs.Nat Rev Genet 14(8), 535-548 (2013).

17. Rottiers V, Naar AM: MicroRNAs in metabolism and metabolic disorders. Nat Rev Mol Cell Biol 13(4), 239-250 (2012).

18. Geisler S, Coller J: RNA in unexpected places: long non-coding RNA functions in diverse cellular contexts.Nat Rev Mol Cell Biol 14(11), 699-712 (2013).

19. Friedman RC, Farh KK, Burge CB, Bartel DP: Most mammalian mRNAs are conserved targets of microRNAs.Genome Res 19(1), 92-105 (2009).

20. Johansson J, Mandin P, Renzoni A, Chiaruttini C, Springer M, Cossart P: An RNA thermosensor controls expression of virulence genes in Listeria monocytogenes.Cell 110(5), 551-561 (2002).

21. Serganov A, Nudler E: A decade of riboswitches.Cell 152(1-2), 17-24 (2013). 


\section{Future
Medicine $\quad$ Peer Review Paper}

22. Loh E, Dussurget 0, Gripenland J et al.: A trans-acting riboswitch controls expression of the virulence regulator PrfA in Listeria monocytogenes.Cell 139(4), 770-779 (2009).

23. Sesto N, Wurtzel O, Archambaud C, Sorek R, Cossart P: The excludon: a new concept in bacterial antisense RNA-mediated gene regulation.Nat Rev Microbiol 11(2), 75-82 (2013).

24. O'neil HS, Marquis H: Listeria monocytogenes flagella are used for motility, not as adhesins, to increase host cell invasion.Infect Immun 74(12), 6675-6681 (2006).

25. Ramos HC, Rumbo M, Sirard JC: Bacterial flagellins: mediators of pathogenicity and host immune responses in mucosa.Trends Microbiol 12(11), 509-517 (2004).

26. Mellin JR, Tiensuu T, Becavin C, Gouin E, Johansson J, Cossart P: A riboswitch-regulated antisense RNA in Listeria monocytogenes.Proc Natl Acad Sci U S A 110(32), 13132-13137 (2013).

27. Buchrieser C, Rusniok C, Kunst F, Cossart P, Glaser P: Comparison of the genome sequences of Listeria monocytogenes and Listeria innocua: clues for evolution and pathogenicity.FEMS Immunol Med Microbiol 35(3), 207-213 (2003).

28. Thiennimitr P, Winter SE, Winter MG et al:: Intestinal inflammation allows Salmonella to use ethanolamine to compete with the microbiota.Proc Natl Acad Sci U S A 108(42), 17480-17485 (2011).

29. Joseph B, Przybilla K, Stuhler C et al:: Identification of Listeria monocytogenes genes contributing to intracellular replication by expression profiling and mutant screening.J Bacteriol 188(2), 556568 (2006).

30. Archambaud C, Nahori MA, Soubigou G et al.: Impact of lactobacilli on orally acquired listeriosis.Proc Natl Acad Sci U S A 109(41), 16684-16689 (2012).

31. Cossart P, Toledo-Arana A: Listeria monocytogenes, a unique model in infection biology: an overview.Microbes Infect 10(9), 1041-1050 (2008).

32. Garcia-Del Portillo F, Calvo E, D'orazio V, Pucciarelli MG: Association of ActA to peptidoglycan revealed by cell wall proteomics of intracellular Listeria monocytogenes.J Biol Chem 286(40), 34675-34689 (2011).

33. Nielsen JS, Lei LK, Ebersbach T et al.: Defining a role for Hfq in Gram-positive bacteria: evidence for Hfq-dependent antisense regulation in Listeria monocytogenes.Nucleic Acids Res 38(3), 907919 (2010).

34. Nielsen JS, Larsen MH, Lillebaek EM et al:: A small RNA controls expression of the chitinase ChiA in Listeria monocytogenes.PLoS One 6(4), e19019 (2011).

35. Chaudhuri S, Gantner BN, Ye RD, Cianciotto NP, Freitag NE: The Listeria monocytogenes ChiA chitinase enhances virulence through suppression of host innate immunity.MBio 4(2), e0061700612 (2013).

36. Nielsen JS, Christiansen $\mathrm{MH}$, Bonde $\mathrm{M}$ et al:: Searching for small sigmaB-regulated genes in Staphylococcus aureus.Arch Microbiol 193(1), 23-34 (2011).

37. Rutherford ST, Bassler BL: Bacterial quorum sensing: its role in virulence and possibilities for its control.Cold Spring Harb Perspect Med 2(11), (2012).

38. Vanderpool CK, Balasubramanian D, Lloyd CR: Dual-function RNA regulators in bacteria.Biochimie 93(11), 1943-1949 (2011).

39. Sorek R, Lawrence CM, Wiedenheft B: CRISPR-mediated adaptive immune systems in bacteria and archaea.Annu Rev Biochem 82, 237-266 (2013).

40. Hain T, Ghai R, Billion A et al:: Comparative genomics and transcriptomics of lineages I, II, and III strains of Listeria monocytogenes.BMC Genomics 13, 144 (2012).

41. Kuenne C, Billion A, Mraheil MA et al: Reassessment of the Listeria monocytogenes pan-genome reveals dynamic integration hotspots and mobile genetic elements as major components of the accessory genome.BMC Genomics 14, 47 (2013).

42. Sesto N, Touchon M, Andrade JM et al: A PNPase Dependent CRISPR System in Listeria.PLoS Genet 10(1), e1004065 (2014).

43. Cardenas PP, Carrasco B, Sanchez H, Deikus G, Bechhofer DH, Alonso JC: Bacillus subtilis polynucleotide phosphorylase 3'-to-5' DNase activity is involved in DNA repair.Nucleic Acids Res 37(12), 4157-4169 (2009).

44. Mick E, Stern A, Sorek R: Holding a grudge: persisting anti-phage CRISPR immunity in multiple human gut microbiomes. RNA Biol 10(5), 900-906 (2013).

45. Rho M, Wu YW, Tang H, Doak TG, Ye Y: Diverse CRISPRs evolving in human microbiomes.PLoS Genet 8(6), e1002441 (2012).

46. Rabinovich L, Sigal N, Borovok I, Nir-Paz R, Herskovits AA: Prophage excision activates Listeria competence genes that promote phagosomal escape and virulence.Cell 150(4), 792-802 (2012). 


\section{Future
Medicine $\quad$ Peer Review Paper}

47. Gripenland J, Netterling S, Loh E, Tiensuu T, Toledo-Arana A, Johansson J: RNAs: regulators of bacterial virulence. Nat Rev Microbiol 8(12), 857-866 (2010).

48. Papenfort K, Vogel J: Regulatory RNA in bacterial pathogens.Cell Host Microbe 8(1), 116-127 (2010).

49. Kim VN, Han J, Siomi MC: Biogenesis of small RNAs in animals.Nat Rev Mol Cell Biol 10(2), 126139 (2009).

50. Fabian MR, Sonenberg N: The mechanics of miRNA-mediated gene silencing: a look under the hood of miRISC.Nat Struct Mol Biol 19(6), 586-593 (2012).

51. Xiao B, Liu Z, Li BS et al:: Induction of microRNA-155 during Helicobacter pylori infection and its negative regulatory role in the inflammatory response.J Infect Dis 200(6), 916-925 (2009).

52. Schulte LN, Eulalio A, Mollenkopf HJ, Reinhardt R, Vogel J: Analysis of the host microRNA response to Salmonella uncovers the control of major cytokines by the let-7 family.Embo J 30(10), 1977-1989 (2011).

53. Sharbati J, Lewin A, Kutz-Lohroff B, Kamal E, Einspanier R, Sharbati S: Integrated microRNAmRNA-analysis of human monocyte derived macrophages upon Mycobacterium avium subsp. hominissuis infection.PLoS One 6(5), e20258 (2011).

54. Schnitger AK, Machova A, Mueller RU et al.: Listeria monocytogenes infection in macrophages induces vacuolar-dependent host miRNA response.PLoS One 6(11), e27435 (2011).

55. Izar B, Mannala GK, Mraheil MA, Chakraborty T, Hain T: microRNA Response to Listeria monocytogenes Infection in Epithelial Cells.Int J Mol Sci 13(1), 1173-1185 (2012).

56. Ma F, Xu S, Liu X et al.: The microRNA miR-29 controls innate and adaptive immune responses to intracellular bacterial infection by targeting interferon-gamma.Nat Immunol 12(9), 861-869 (2011).

57. Archambaud C, Sismeiro 0, Toedling J et al:: The intestinal microbiota interferes with the microRNA response upon oral Listeria infection.MBio 4(6), e00707-00713 (2013).

58. Kurashige J, Kamohara H, Watanabe $\mathrm{M}$ et al.: MicroRNA-200b regulates cell proliferation, invasion, and migration by directly targeting ZEB2 in gastric carcinoma.Ann Surg Oncol 19 Suppl 3, S656-664 (2012).

59. Baud J, Varon C, Chabas S, Chambonnier L, Darfeuille F, Staedel C: Helicobacter pylori initiates a mesenchymal transition through ZEB1 in gastric epithelial cells.PLoS One 8(4), e60315 (2013).

60. Taganov KD, Boldin MP, Chang KJ, Baltimore D: NF-kappaB-dependent induction of microRNA miR-146, an inhibitor targeted to signaling proteins of innate immune responses.Proc Natl Acad Sci U S A 103(33), 12481-12486 (2006).

61. O'connell RM, Taganov KD, Boldin MP, Cheng G, Baltimore D: MicroRNA-155 is induced during the macrophage inflammatory response.Proc Natl Acad Sci U S A 104(5), 1604-1609 (2007).

62. Pamer EG: Immune responses to Listeria monocytogenes.Nat Rev Immunol 4(10), 812-823 (2004).

63. Lind EF, Elford AR, Ohashi PS: Micro-RNA 155 is required for optimal CD8+ T cell responses to acute viral and intracellular bacterial challenges.J Immunol 190(3), 1210-1216 (2013).

64. Ma X, Becker Buscaglia LE, Barker JR, Li Y: MicroRNAs in NF-kappaB signaling.J Mol Cell Biol 3(3), 159-166 (2011).

65. Liu Z, Xiao B, Tang B et al.: Up-regulated microRNA-146a negatively modulate Helicobacter pylori-induced inflammatory response in human gastric epithelial cells.Microbes Infect 12(11), 854-863 (2010).

66. Monk CE, Hutvagner G, Arthur JS: Regulation of miRNA transcription in macrophages in response to Candida albicans.PLoS One 5(10), e13669 (2010).

67. Mrazek J, Kreutmayer SB, Grasser FA, Polacek N, Huttenhofer A: Subtractive hybridization identifies novel differentially expressed ncRNA species in EBV-infected human B cells.Nucleic Acids Res 35(10), e73 (2007).

68. Hamilton HL, Dominguez NM, Schwartz KJ, Hackett KT, Dillard JP: Neisseria gonorrhoeae secretes chromosomal DNA via a novel type IV secretion system.Mol Microbiol 55(6), 1704-1721 (2005).

69. Woodward JJ, Iavarone AT, Portnoy DA: c-di-AMP secreted by intracellular Listeria monocytogenes activates a host type I interferon response.Science 328(5986), 1703-1705 (2010).

70. Abdullah Z, Schlee M, Roth S et al:: RIG-I detects infection with live Listeria by sensing secreted bacterial nucleic acids.Embo J 31(21), 4153-4164 (2012).

71. Cazalla D, Yario T, Steitz JA: Down-regulation of a host microRNA by a Herpesvirus saimiri noncoding RNA.Science 328(5985), 1563-1566 (2010).

72. Libri V, Helwak A, Miesen P et al: Murine cytomegalovirus encodes a miR-27 inhibitor disguised as a target.Proc Natl Acad Sci U S A 109(1), 279-284 (2012). 


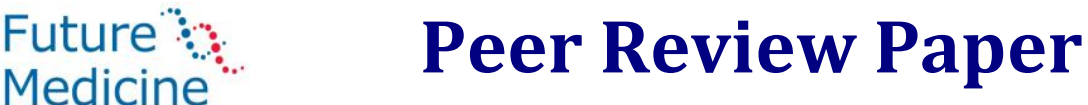

73. Marcinowski L, Tanguy M, Krmpotic A et al: Degradation of cellular mir-27 by a novel, highly abundant viral transcript is important for efficient virus replication in vivo.PLoS Pathog 8(2), e1002510 (2012).

74. Weiberg A, Wang M, Lin FM et al.: Fungal small RNAs suppress plant immunity by hijacking host RNA interference pathways.Science 342(6154), 118-123 (2013).

75. Sander LE, Davis MJ, Boekschoten MV et al:: Detection of prokaryotic mRNA signifies microbial viability and promotes immunity.Nature 474(7351), 385-389 (2011).

76. Hagmann CA, Herzner AM, Abdullah Z et al:: RIG-I detects triphosphorylated RNA of Listeria monocytogenes during infection in non-immune cells.PLoS One 8(4), e62872 (2013).

77. Lenz LL, Mohammadi S, Geissler A, Portnoy DA: SecA2-dependent secretion of autolytic enzymes promotes Listeria monocytogenes pathogenesis.Proc Natl Acad Sci U S A 100(21), 12432-12437 (2003).

78. Machata S, Hain T, Rohde M, Chakraborty T: Simultaneous deficiency of both MurA and p60 proteins generates a rough phenotype in Listeria monocytogenes.J Bacteriol 187(24), 8385-8394 (2005).

\section{Reference annotations}

* Cossart P: Illuminating the landscape of host-pathogen interactions with the bacterium Listeria monocytogenes.Proc Natl Acad Sci U S A 108(49), 19484-19491 (2011).

Comprehensive review on Listeria monocytogenes infection and interaction with the host.

* Caldelari I, Chao Y, Romby P, Vogel J: RNA-mediated regulation in pathogenic bacteria.Cold Spring Harb Perspect Med 3(9), a010298 (2013).

Comprehensive review on regulatory RNAs in pathogenic bacteria.

** Toledo-Arana A, Dussurget 0, Nikitas G et al:: The Listeria transcriptional landscape from saprophytism to virulence. Nature 459(7249), 950-956 (2009).

Extensive tiling array-based transcriptomic analysis of Listeria grown in multiple conditions relevant for the virulence process.

* Mraheil MA, Billion A, Mohamed W et al:: The intracellular sRNA transcriptome of Listeria monocytogenes during growth in macrophages.Nucleic Acids Res 39(10), 4235-4248 (2011).

Extensive deep sequencing-based transcriptomic analysis of intracellular Listeria that led to identification of several RNAs important for the virulence process.

** Johansson J, Mandin P, Renzoni A, Chiaruttini C, Springer M, Cossart P: An RNA thermosensor controls expression of virulence genes in Listeria monocytogenes. Cell 110(5), 551-561 (2002).

Discovery of the RNA thermosensor regulating expression of main Listeria virulence regulator PrfA.

** Loh E, Dussurget 0, Gripenland J et al: A trans-acting riboswitch controls expression of the virulence regulator PrfA in Listeria monocytogenes.Cell 139(4), 770-779 (2009).

Discovery of the trans-acting SAM riboswitch regulating production of the main Listeria virulence regulator PrfA.

* $\quad$ Sesto N, Wurtzel O, Archambaud C, Sorek R, Cossart P: The excludon: a new concept in bacterial antisense RNA-mediated gene regulation.Nat Rev Microbiol 11(2), 75-82 (2013).

Progress article highlighting a new asRNA-mediated mechanism of bacterial gene regulation named "excludon".

** Mellin JR, Tiensuu T, Becavin C, Gouin E, Johansson J, Cossart P: A riboswitch-regulated antisense RNA in Listeria monocytogenes.Proc Natl Acad Sci U S A 110(32), 13132-13137 (2013).

Functional characterization of a B12 riboswitch-regulated asRNA in Listeria.

** Sesto N, Touchon M, Andrade JM et al: A PNPase Dependent CRISPR System in Listeria.PLoS Genet 10(1), e1004065 (2014).

Shows polynucleotide phosphorylase (PNPase)has a funcional role in CRISPR activity in Listeria.

** Archambaud C, Sismeiro 0, Toedling J et al:: The intestinal microbiota interferes with the microRNA response upon oral Listeria infection.MBio 4(6), e00707-00713 (2013).

Comprehensive in vivo study of miRNA expression response upon orally acquired listeriosis.

** Abdullah Z, Schlee M, Roth S et al: RIG-I detects infection with live Listeria by sensing secreted bacterial nucleic acids.Embo J 31(21), 4153-4164 (2012). 


\section{Future
Medicine $\quad$ Peer Review Paper}

Shows Listeria nucleic acids are released during the host cell infection via SecA2 dependent pathway.

Figures:

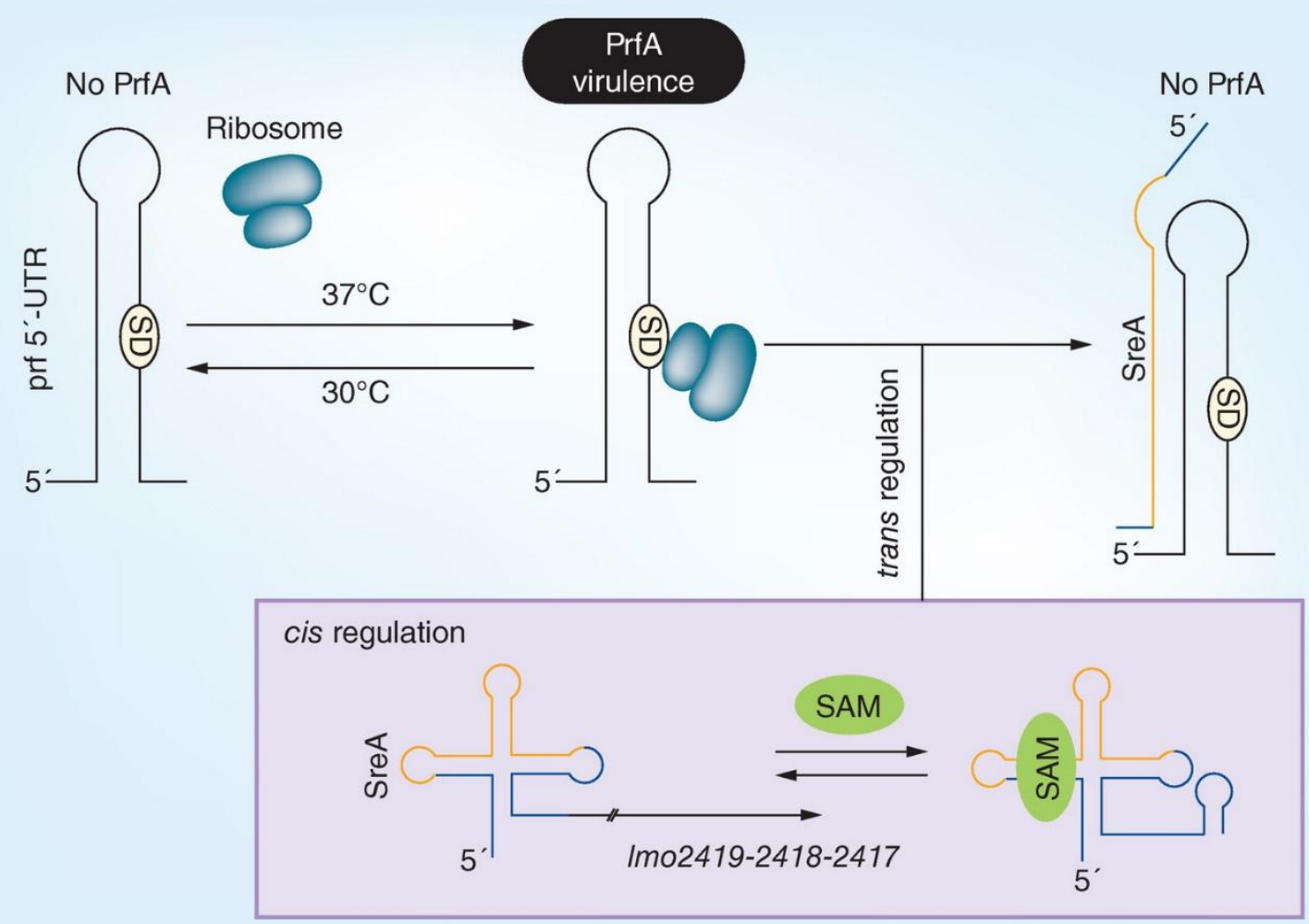

Figure 1. 5'UTR-mediated regulation of PrfA expression.

710 At temperatures below $37^{\circ} \mathrm{C}$, the $5^{\prime} \mathrm{UTR}$ of $\operatorname{prfAmRNA}$ forms a stable hairpin structure

711 that occludes the Shine-Dalgarno sequence (SD) and prevents binding of the ribosome.

712 At $37^{\circ} \mathrm{C}$ this structure melts, allowing the ribosome to bind and produce the PrfA protein

713 that activates expression of many virulence genes. In addition, at $37^{\circ} \mathrm{C}$ the transcript

714 generated by theS-adenosyl-methionine (SAM) riboswitch (SreA) interacts with the prfA5'-UTR and prevents the production of the PrfA protein. 


\section{Future es $\quad$ Peer Review Paper}

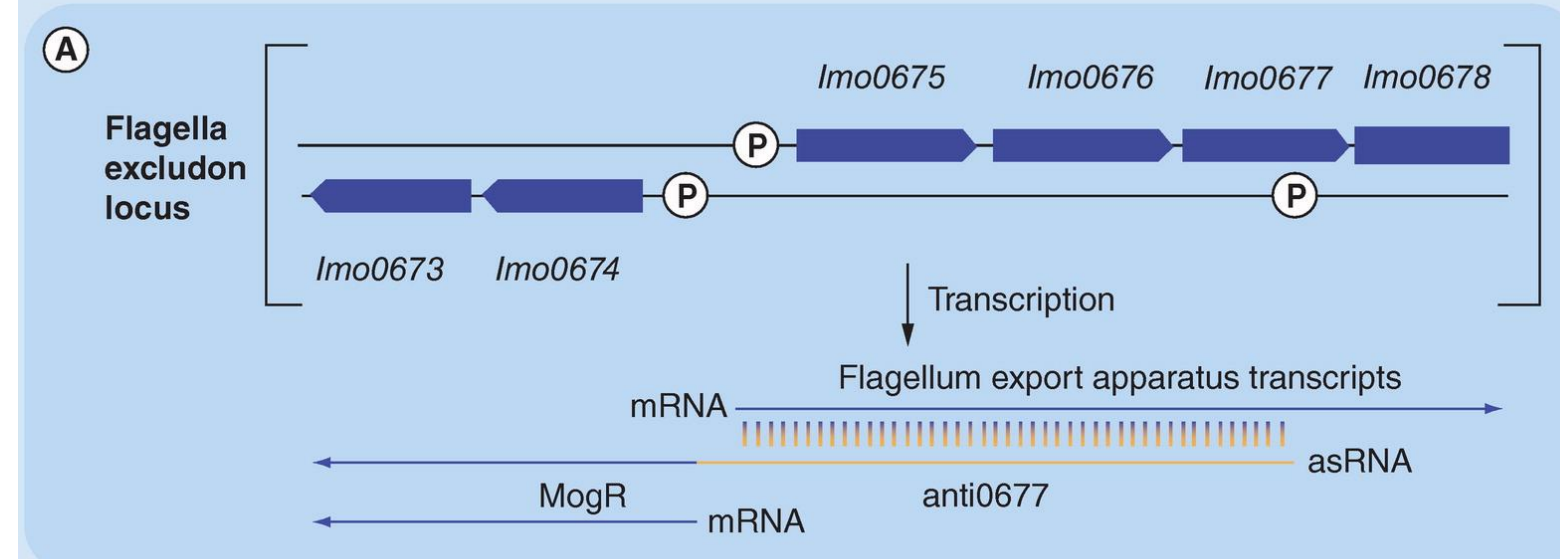

(B)

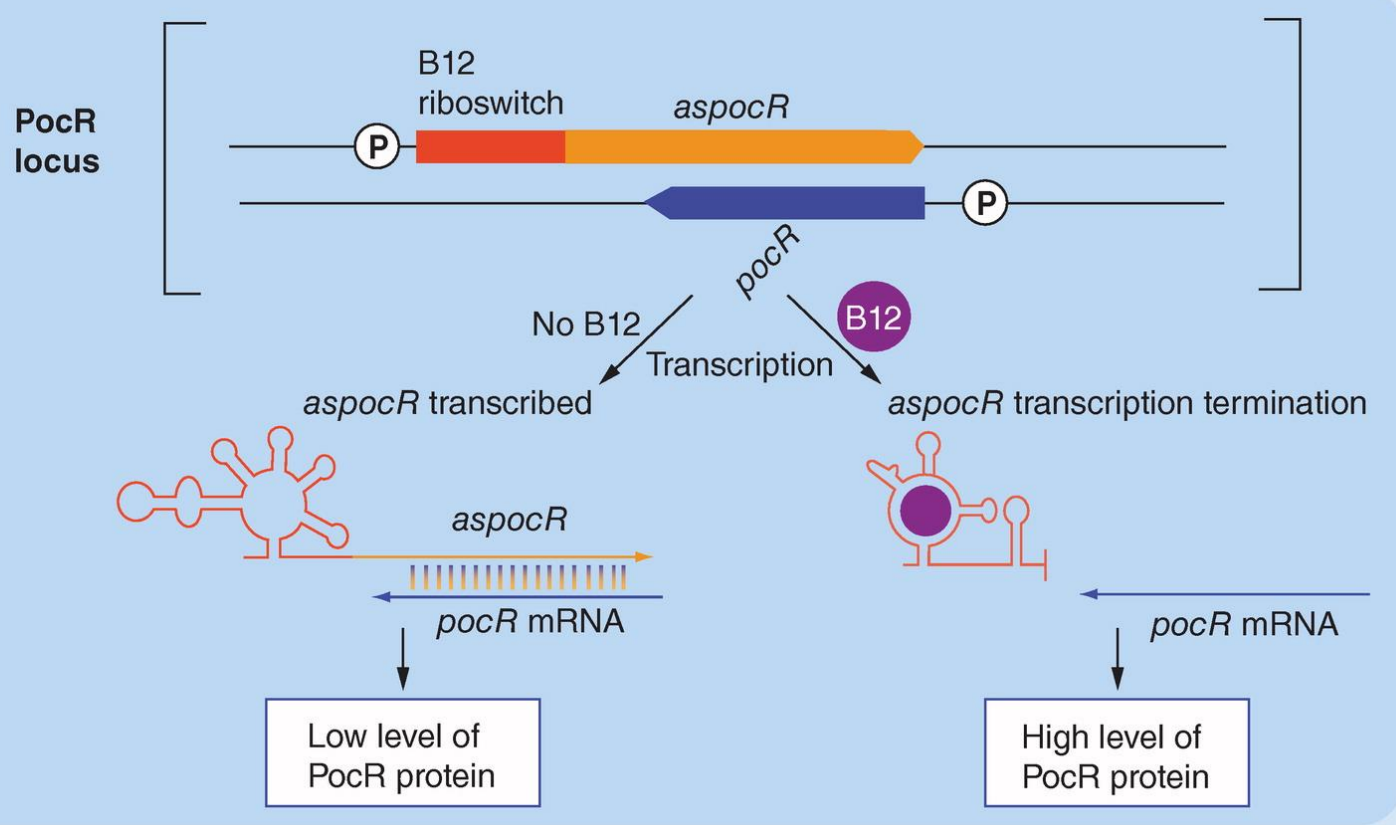

717 Figure 2. The asRNA-mediated mechanisms of gene regulation in Listeria

718 A)Example of an excludon, where a long asRNA Anti0677 overlaps and serves as an 719 antisense regulator of Imo0675,Imo0676 and Imo0677 encoding FliN, FliP and FliQ, 720 respectively, which are components of the flagellum export apparatus, while

721 simultaneously encompassing the 5'-UTR and the mRNA of Imo0674 encoding MogR,a

722 transcriptional repressor of the flagellum genes. The expression of Anti0677 is regulated

723 by sigmaB $(\sigma B$, a stress-activated transcriptional regulator). Altogether, the excludon

724 ensures that by two mechanisms (inhibition mediated by the antisense component of 725 anti0677; and repression mediated by increased expression of the MogR repressor) 


\section{\begin{tabular}{l}
$\begin{array}{l}\text { Future } \\
\text { Medicine }\end{array}$ Peer Review Paper \\
\hline
\end{tabular}}

miR-192 ${ }^{\dagger}$ miR-200b miR-215 miR-143 $\mathrm{miR}-148 \mathrm{a}^{\ddagger}$ miR-194 miR-200b miR-200c ${ }^{\ddagger}$ miR-378

Intestinal tissue Archambaud et al. (2012) Archambaud et al. (2013)

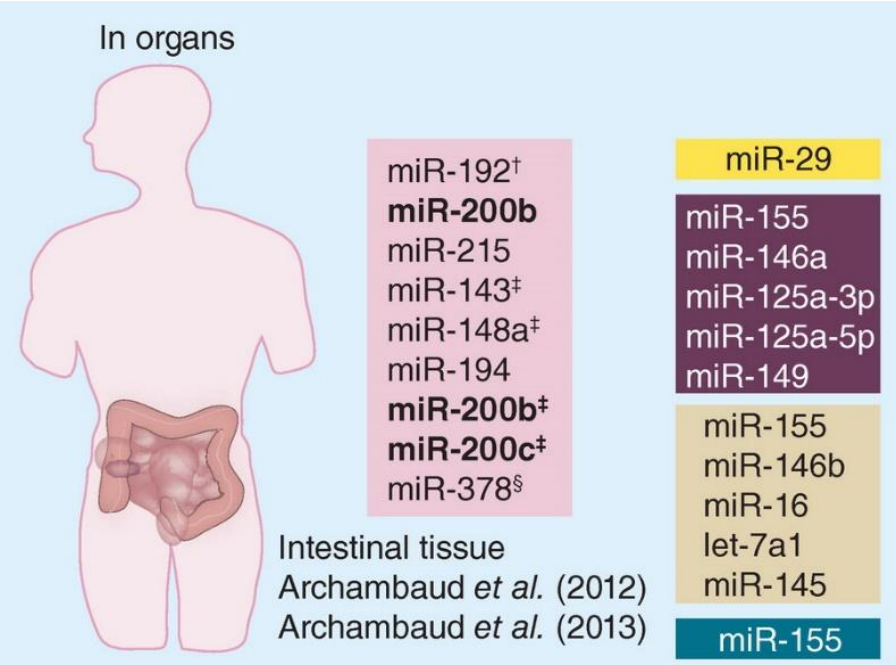

In cells

miR-155
miR-146a
miR-125a-3p
miR-125a-5p
miR-149
miR-155
miR-146b
miR-16
let-7a1
miR-145
miR-155

Natural killer cells Ma et al. (2011)

Bone marrow-derived macrophages Schnither et al. (2011)

Epithelial cells Izar et al. (2011)

CD8 ${ }^{+} \mathrm{T}$ cells Lind et al. (2011)

Figure 3. Regulation of the host miRNA expression during Listeria infection.

Schematic representation of the significantly regulated miRNAs in the intestinal tissue during orally acquired listeriosis (grey) and in infected cell lines (blue, purple, orange and green). Highlighted are the miRNAs whose expression is modulated by the presence of the host microbiota or lactobacilli: expression decrease upon L. monocytogenes infection and expression increase upon treatment with Lactobacillus $\left(^{*}\right)$, expression decrease only in the presence of microbiota upon L. monocytogenes infection (**), expression decrease in the presence of microbiota and expression increase in the absence of microbiota mice upon L. monocytogenes infection (***).In bold are miRNAs detected to vary during different infections. 


\section{Future
Medicine $\quad$ Peer Review Paper}

\begin{tabular}{|c|c|c|c|}
\hline $\begin{array}{l}\text { Type of RNA } \\
\text { regulator }\end{array}$ & $\begin{array}{l}\text { Specific } \\
\text { name }\end{array}$ & Study (year) & Ref. \\
\hline \multicolumn{4}{|l|}{ 5'-UTR } \\
\hline Thermosensor & $\begin{array}{l}5^{\prime} \text {-UTR prfA } \\
\text { mRNA }\end{array}$ & Johansson et al. (2002) & {$[20]$} \\
\hline $\begin{array}{l}\text { Trans-acting } \\
\text { riboswitch }\end{array}$ & SAM SreA & Loh et al. (2009) & {$[21]$} \\
\hline \multicolumn{4}{|c|}{ Cis-encoded asRNAs } \\
\hline Excludon & Anti0677 & $\begin{array}{l}\text { Toledo-Arana et al. (2009), } \\
\text { Wurtzel et al. (2012), Sesto et } \\
\text { al. (2013) }\end{array}$ & {$[12,13,22$} \\
\hline $\begin{array}{l}\text { Riboswitch- } \\
\text { regulated asRNA }\end{array}$ & Anti-PocR & Mellin et al. (2013) & {$[23]$} \\
\hline \multicolumn{4}{|c|}{ Trans-encoded sRNAs } \\
\hline & $\begin{array}{l}\text { Rli31, Rli33-2 } \\
\text { Rli50 }\end{array}$ & Mraheil et al. (2011) & {$[10]$} \\
\hline & Rli38 & Toledo-Arana et al. (2009) & {$[12]$} \\
\hline & Rli27 & Quereda et al. (2014) & [34] \\
\hline & LhrA & Christiansen et al. (2006) & [7] \\
\hline \multicolumn{4}{|l|}{ CRISPR } \\
\hline & rliB-CRISPR & Sesto et al. (2014) & {$[24]$} \\
\hline
\end{tabular}

Table 1. RNA-mediated regulatory mechanisms related to Listeria virulence 